\title{
Removal of phenanthrene from coastal waters by green tide algae Ulva prolifera
}

\author{
Cui Zhang ${ }^{\mathrm{a}, \mathrm{b}}$, Jian $\mathrm{Lu}^{\mathrm{a}, \mathrm{b}, *}$, Jun $\mathrm{Wu}^{\mathrm{b}, \mathrm{c}}$, Yongming Luo ${ }^{\mathrm{a}}$
}

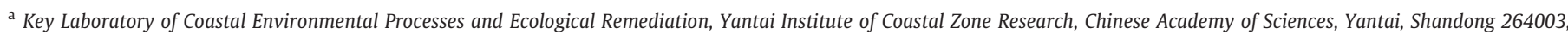
People's Republic of China

b University of Chinese Academy of Sciences, Beijing 100049, People's Republic of China

c Qinghai Institute of Salt Lakes, Chinese Academy of Sciences, Xining, Qinghai 810008, People's Republic of China

\section{H I G H L I G H T S}

- Phenanthrene was removed efficiently by green tide algae Ulva prolifera.

- Nutrient and temperature had positive influence on the removal of phenanthrene.

- $91.3 \%$ of phenanthrene was removed under the initial concentration of 5 $\mu \mathrm{g} \mathrm{L}{ }^{-1}$.

- New phenanthrene attenuation process associated with green tide was confirmed.

\section{G R A P H I C A L A B S T R A C T}

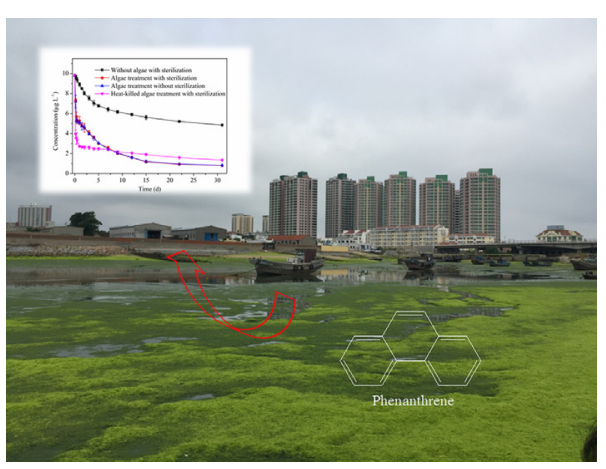

\section{A R T I C L E I N F O}

\section{Article history:}

Received 30 May 2017

Received in revised form 20 July 2017

Accepted 21 July 2017

Available online $\mathrm{xxxx}$

\section{Keywords:}

Ulva prolifera

Green tide

Phenanthrene

Natural attenuation

Phytoremediation

Seawater

\begin{abstract}
A B S T R A C T
Ulva prolifera (U. prolifera) has been frequently involved in terrible algal proliferation in coastal areas. Although it is known to be associated with green tide, its contribution to the natural attenuation of the polycyclic aromatic hydrocarbons (PAHs) in seawater has not been evaluated. In this study, the removal of phenanthrene using $U$. prolifera collected from coastal water with green tide blooming was investigated. The results showed that phenanthrene could be removed efficiently in the presence of both the live and heat-killed $U$. prolifera. The phenanthrene concentrations of the live algae treatment decreased smoothly from 10.00 to $0.80 \mu \mathrm{g} \mathrm{L}{ }^{-1}$ through the whole process, while those of the heat-killed algae treatment decreased sharply from 10.0 to $2.71 \mu \mathrm{g} \mathrm{L}^{-1}$ in one day and kept constantly after that. The in situ monitoring and visualizing using laser confocal scanning microscopy (LCSM) confirmed the accumulation of phenanthrene in $U$. prolifera. The increase in nutrient and temperature led to the increase of phenanthrene removal rate, while the salinity had less influence on the removal of phenanthrene. The removal efficiency by $U$. prolifera had a good linear relationship with phenanthrene initial concentration $\left(r^{2}=0.999\right)$ even at $100 \mu \mathrm{L} \mathrm{L}^{-1}$ which was higher than its environmentally relevant concentrations. High removal efficiency (91.3\%) was observed when the initial phenanthrene concentration was set at environmental relevant concentration $\left(5 \mu \mathrm{g} \mathrm{L}^{-1}\right.$ ). Results of this study demonstrate a potential new natural attenuation process for typical PAHs in coastal water during the outbreak of green tide. These findings indicate that the outbreak of harmful green tide algae may bring positive environmental benefits in the terms of the removal of harmful organic pollutants from coastal waters.
\end{abstract}

(c) 2017 Elsevier B.V. All rights reserved.

\footnotetext{
* Corresponding author at: Key Laboratory of Coastal Environmental Processes and Ecological Remediation, Yantai Institute of Coastal Zone Research, Chinese Academy of Sciences, Yantai 264003, People's Republic of China.

E-mail address: jlu@yic.ac.cn (J. Lu).
} 


\section{Introduction}

Algal blooms have become a global problem, resulting in loss of water clarity, production of bad taste and odor and toxins that lead to adverse effects on aquatic organism (Wu et al., 2010a; Wu et al., 2011; Wu et al., 2010b). In every spring and early summer since 2007, green tides persistently flourish along the coastal regions of the northern Yellow Sea, Jiangsu Province of China (Shi et al., 2015), and then floated northward until landed on seashore of Shandong Province with 6 million $\mathrm{kg}$ algae biomass, which brought negative effects on local economy and coastal ecosystems (Zhang et al., 2011). As a kind of dominant species, Ulva prolifera (U. prolifera) can inhabit in the inshore and estuaries as well as brackish and fresh waters which contain enriched nutrients from agriculture and animal aquaculture (Li et al., 2016). These algae consist of filamentous shoots with monostromatic hollow cylinders and have higher ratio of surface to volume (S/V), which endows them with high nutrient (nitrogen and phosphorus) uptake capability and the potential to remove pollutants when exposed to contaminated aquatic environment (Gao et al., 2016). Many laboratory experiments have indicated that $U$. prolifera can fast uptake nitrogen and phosphorus (Fan et al., 2014; Luo et al., 2012; Xu et al., 2016). It is also suggested that during the mid- to late period of the macroalgal blooms, $U$. prolifera can continue to remove nutrients such as $\mathrm{N}$ and $\mathrm{P}$ from seawater (Li et al., 2016; Zhu et al., 2016). However, few reports are available on the removal of organic toxic contaminants by $U$. prolifera during the macroalgal blooms.

Polycyclic aromatic hydrocarbons (PAHs) are a major group of persistent organic contaminants, which can exist for a long time and undergo long-range transport in the environment (Zhao et al., 2015). So far $>100$ PAH congeners have been identified and 16 PAH congeners are classified as priority pollutants by the European Union and US Environmental Protection Agency (US EPA) (Xia et al., 2012). PAHs enter into the environment through diverse natural and anthropogenic activities such as forest fires, incomplete combustion of fossil fuels, waste incineration, industrial effluent, urban runoff, oil spills, and atmospheric fallout (Augusto et al., 2010; Suman et al., 2016; Wang et al., 2012). PAHs in marine environments have triggered extensive public concerns and scientific interests owing to its carcinogenicity, mutagenicity, and teratogenicity (Kim et al., 2013). These pollutants not only pose risk to fish and other aquatic organisms, but also bioaccumulate in marine organisms with possible transfer to humans via food chains (Luo et al., 2014; Zhang et al., 2017). PAHs may undergo many natural attenuation processes including adsorption, volatilization, photolysis, and chemical degradation (Haritash and Kaushik, 2009). Among these processes, biodegradation has been suggested as the major pathway for the decontamination of PAHs in nature (Haritash and Kaushik, 2009; Juhasz and Naidu, 2000). Besides bacteria (Pugazhendi et al., 2017; Wang et al., 2017), PAHs can also be biodegraded by algae (Chan et al., 2010; Diaz et al., 2015; Luo et al., 2014). An integrated approach of physical, chemical, and biological degradation may be adopted to get synergistically enhanced PAHs removal rates and to treat/remediate the contaminated sites in an ecologically favorable process (Haritash and Kaushik, 2009). Although bioremediation is capable of delivering long-lasting and low-cost solutions for PAHs pollution control, the remediation of coastal water polluted with PAHs at large scale is still a challenge.

Among the PAHs, phenanthrene (PHE) which has three aromatic rings per molecule, is known as a highly reactive compound, a human skin photosensitizer and mild allergen, and a potent inhibitor of gap junction intercellular communications (Sinha et al., 2012). Although $U$. prolifera is known to be associated with green tide, its ability to remove typical PAHs has not been evaluated. In this study, the removal of typical PAHs (PHE) using green tide algae U. prolifera was firstly investigated. The influence of different environmental factors on the removal of PHE was also evaluated. The final goal was to obtain initial information on the potential positive environmental benefit in the terms of the removal of harmful organic pollutants from coastal waters during the outbreak of harmful green tide algae. PHE was chosen as a representative compound of PAHs to discuss U. prolifera's environmental effects because 1 ) it is difficult to be bioremoved due to its low water solubility (1.29 $\mathrm{mg} \mathrm{L}^{-1}$ ) (Pedetta et al., 2013); 2) it has been detected with high frequency and concentration, ranging from $n \mathrm{~L}^{-1}$ in surface water or groundwater (Zhu et al., 2014) to $\mu^{-1} \mathrm{~L}^{-1}$ in several oil spill area (D'Sa et al., 2016); and 3) it is a model carcinogenic PAHs containing both "bay-region" and "K-region" (Muratova et al., 2015).

\section{Material and methods}

\subsection{Reagents and materials}

Phenanthrene (PHE, purity > 99\%) was purchased from Aladdin (Shanghai, China). Phenanthren- $d_{10}$ purchased from Dr. Ehrenstorfer GmbH (Augsburg, Germany) was used as internal standard in GC-MS analysis. Methanol, acetonitrile, acetone, and dichloromethane used for ultra high performance liquid chromatography (UHPLC) and gas chromatography-mass spectrometry (GC-MS) were HPLC grade. Sodium nitrate, sodium hypochlorite, and sodium hydrogen phosphate were analytical reagents and used without further purification. Anhydrous sodium sulfate was analytical reagents and dried in a muffle furnace at $450{ }^{\circ} \mathrm{C}$ for $4 \mathrm{~h}$ prior to use. The stock solution of PHE $\left(1 \mathrm{~g} \mathrm{~L}^{-1}\right)$ was weekly prepared by dissolving an appropriate amount of PHE in methanol in a volumetric flask and diluted with sterile sea water to target concentration before use.

\subsection{U. prolifera and seawater for experiments}

U. prolifera was collected in July 2016 from the coastal water (Rushan City, China) where there was an outbreak of green tide. In the laboratory, these algae were washed several times with sterile seawater, sterilized with $1 \%$ sodium hypochlorite for $2 \mathrm{~min}$, and then rinsed with autoclaved seawater. U. prolifera was pre-cultured in plastic case with natural seawater without additional nutrients. U. prolifera was incubated at $10{ }^{\circ} \mathrm{C}$ with a dark/light cycle of $12 / 12$ under an irradiance of $100 \mu \mathrm{mol}$ photons $\mathrm{m}^{-2} \mathrm{~s}^{-1}$ in GXZ-380B-LED temperature controlled incubator (Ningbo Jiangnan Inc., China), and transferred to an experimental incubator at a constant temperature of $20^{\circ} \mathrm{C}$ under the same incubation condition for $72 \mathrm{~h}$ before running experiments. The incubated medium was completely renewed every week. Seawater was obtained from the coast of Yantai, China. Natural seawater was filtered through glass fiber papers (Whatman $\mathrm{GF} / \mathrm{C}, 0.22 \mu \mathrm{m}$ pore size) to eliminate organic particles and debris of organisms. This seawater was used for culture macroalgae in all experiments of this study.

\subsection{Experimental setup}

The removal efficiency of PHE from the solution by $U$. prolifera under different environmental factors was investigated in $500 \mathrm{~mL}$ beaker containing $400 \mathrm{~mL}$ sterilized seawater with relevant concentrations of PHE and algae. Each beaker was covered with sealing film to minimize the abiotic loss of PHE but allowed sufficient gas exchange during the experiment. All beakers were shaken twice at a set time every day to promote the mass transfer process.

For live treatment, the algae $\left(4.0 \mathrm{~g} \mathrm{~L}^{-1}\right)$ were added into beaker. For the heat-killed treatment, algae with the same mass as the live treatment were autoclaved at $121^{\circ} \mathrm{C}$ for $20 \mathrm{~min}$ before the assay. The beakers without any algae were used as the abiotic controls for monitoring any abiotic loss of PHE. The initial concentration of PHE $\left(10 \mu \mathrm{g} \mathrm{L}^{-1}\right)$ were obtained by diluting the stock solution of PHE $\left(1 \mathrm{~g} \mathrm{~L}^{-1}\right)$ with sterile sea water. Water and algae samples were collected at given time intervals, and the residual amounts of PHE in the media and the algal cells were determined. $0.5 \mathrm{~mL}$ aliquots were put into centrifuge tube containing $0.5 \mathrm{~mL}$ acetonitrile and centrifuged at 12,000 rpm for $6 \mathrm{~min}$ before UHPLC analysis. 
Intertidal macroalgae are subject to fluctuations in physicochemical variables such as high light intensities, high (or low) salinity, temperature, nutrient deficiency, and desiccation (Cabello-Pasini et al., 2011), which may influence the uptake of organic pollutant in the algae. To explore the effect of different light regimes, the algae were exposed to darkness, a photoperiod 12:12 (light:darkness) and continuous light, i.e., a $24 \mathrm{~h}$ photoperiod. In order to evaluate the effect of salinity on the removal of PHE, the salinity of seawater was set as 16,24 , and $32 \mathrm{~g} \mathrm{~L}^{-1}$. Seawater with lower salinity was prepared by diluting seawater with salinity of $32 \mathrm{~g} \mathrm{~L}^{-1}$ with corresponding volume of distilled water. To investigate the influence of nutrient, a certain amount of sodium nitrate and sodium hydrogen phosphate stock solution $(20 \mathrm{mM}$ $\mathrm{NO}_{3}^{-} / 2 \mathrm{mM} \mathrm{PO}_{4}^{2-}$ ) was added to reach nutrient concentration of $0 \mu \mathrm{M}$ $\left(\mathrm{NO}_{3}^{-}\right) / 0 \mu \mathrm{M}\left(\mathrm{PO}_{4}^{2-}\right), 50 \mu \mathrm{M}\left(\mathrm{NO}_{3}^{-}\right) / 5 \mu \mathrm{M}\left(\mathrm{PO}_{4}^{2-}\right)$ and $150 \mu \mathrm{M}\left(\mathrm{NO}_{3}^{-}\right) /$ $15 \mu \mathrm{M}\left(\mathrm{PO}_{4}^{2-}\right)$. In addition, temperature was adjusted by temperature controlled incubator to $10^{\circ} \mathrm{C}, 20^{\circ} \mathrm{C}$ and $30^{\circ} \mathrm{C}$ to observe the PHE removal efficiency by $U$. prolifera. To evaluate the influence of PHE initial concentration on removal efficiency, various initial concentrations of PHE were obtained by diluting the stock solution of PHE $\left(1 \mathrm{~g} \mathrm{~L}^{-1}\right)$ with sterile sea water to $5,10,20,50$, and $100 \mu \mathrm{L} \mathrm{L}^{-1}$. Algae-free controls experiments were also performed when evaluating the effect of abiotic factors (temperature, salinity, and nutrients) and there was no significant difference between these algae-free controls under different abiotic factors and none-algae with sterilization control group $\left(\mathrm{CK}_{1}\right)$ (not shown in results).

\subsection{Extraction of PHE in macroalgae}

To perform the extraction procedure, $2 \mathrm{~g}$ of fresh algae sample was powdered and homogenized with $5 \mu \mathrm{L}$ internal standard solution (phenanthren- $d_{10}, 100 \mathrm{mg} \mathrm{L}^{-1}$ ), and then ultrasonically extracted with $30 \mathrm{~mL}$ methylenechloride/acetone $(1: 1 \mathrm{v} / \mathrm{v})$ at room temperature for $15 \mathrm{~min}$. The extracted liquid was cleaned using $2 \mathrm{~g}$ of anhydrous sodium sulfate and concentrated with a nitrogen evaporator until nearly dry, then reconstituted with $1.0 \mathrm{~mL}$ of dichloromethane prior to GCMS analysis.

\subsection{Analytical methods}

The residual concentrations of PHE in water samples were monitored by a ACQUITY UHPLC system (Waters, Milford, USA) equipped with a C18 reverse phase column $(2.1 \times 50 \mathrm{~mm}, 1.7 \mu \mathrm{m})$ with $\mathrm{H}_{2} \mathrm{O}$ /acetonitrile $(20 / 80, \mathrm{v} / \mathrm{v} \%)$ as the mobile phase at a flow rate of $0.3 \mathrm{~mL} \mathrm{~min}{ }^{-1}$. The injection volume was $10 \mu \mathrm{L}$, and the fluorescence of eluted compounds was monitored at $388 \mathrm{~nm}$ with excitation at $242 \mathrm{~nm}$ using a fluorescence detector (Waters, Milford, USA).

Algae samples acquired through extraction were analyzed by Agilent 7820A GC system (Agilent technologies Inc., Palo Alto, CA, USA) with a M7 single quadrupole MS system from Persee Co. (Beijing, China), equipped with a $30 \mathrm{~m} \times 0.25 \mathrm{~mm}$ I.D. DB-5MS column (Agilent J\&W Scientific, Palo Alto, CA, USA) coated with 5\% diphenylpoly dimethyl siloxane (film thickness $0.25 \mu \mathrm{m}$ ). The injector was operated at $280{ }^{\circ} \mathrm{C}$ in splitless mode. Helium ( $>99.999 \%$ pure) was used as carrier gas at $1.0 \mathrm{~mL} \mathrm{~min}^{-1}$ during the whole run. The temperatures of the transfer line and ion source were held at $280{ }^{\circ} \mathrm{C}$ and $230{ }^{\circ} \mathrm{C}$. The column oven temperature program started at $100{ }^{\circ} \mathrm{C}$ for $1 \mathrm{~min}$, then programmed to $200{ }^{\circ} \mathrm{C}$ at a $20{ }^{\circ} \mathrm{C} \mathrm{min}^{-1}$ and held for $1 \mathrm{~min}$, finally to $290{ }^{\circ} \mathrm{C}$ at $30{ }^{\circ} \mathrm{C} \mathrm{min}^{-1}$ rate, and held for 5 min to comprise a total runtime of $14.57 \mathrm{~min}$, including a 6 min solvent cut for all analyses. All target compounds were identified by full scan mode $(\mathrm{m} / \mathrm{z} 50-400)$ based on their mass spectra and GC retention times. Subsequent acquisition and quantification was performed by a time scheduled selective ion monitoring (SIM) program. The quantitative and qualitative ions for PHE are $m / z 176,178$, and 179 , and that of phenanthren- $d_{10}$ are $m / z 187,188$, and 189 . The recovery for PHE was $81 \%$.
To visualize the locations of PHE in live and heat-killed algae, the algae samples were observed with a laser scanning confocal microscope (LCSM, Olympus Fluoview FV1000, 40× objective lens). The laser wavelength of the LCSM was set at $405 \mathrm{~nm}$. Images of PHE in/on the tissues of $U$. prolifera were collected and processed using the Olympus Fluoview Ver.2.1c Viewer software.

\subsection{Data analysis}

All experiments were performed in triplicate with independent replication of data $(n=3)$. The results were analyzed by using Origin 8.5 and SPSS 20.0. One-way ANOVA and Tukey's multiple comparisons were employed to compare the differences in the PHE removal efficiency among various treatments. The significance level was set at 0.05 .

\section{Results and discussion}

\subsection{The removal of PHE using U. prolifera}

The removal of PHE by U. prolifera was observed during the incubation period (Fig. 1). After 31 days incubation, the concentrations of PHE in the culture medium of the none-algae with sterilization control group $\left(\mathrm{CK}_{1}\right)$, heat-killed $U$. prolifera $\left(\mathrm{CK}_{2}\right)$, the algae-added with sterilization $\left(\mathrm{T}_{1}\right)$, and algae-added without sterilization $\left(\mathrm{T}_{2}\right)$, reduced from 10.00 $\mu \mathrm{g} \mathrm{L}{ }^{-1}$ to $4.84,1.34,0.80$, and $0.82 \mu \mathrm{g} \mathrm{L}{ }^{-1}$, respectively. The removal efficiencies were $51.6 \%, 86.6 \%, 92.0 \%$, and $91.8 \%$ for $\mathrm{CK}_{1}, \mathrm{CK}_{2}, \mathrm{~T}_{1}$, and $\mathrm{T}_{2}$, respectively. The removal of PHE in the control treatment showed that the abiotic loss of PHE (mainly through photodegradation and volatilization) (Luo et al., 2014; Shang et al., 2015) could beyond 50\%. The removal efficiency of PHE in the U. prolifera treatment was much higher than that in the control treatment, indicating that $U$. prolifera was engaged in the removal of PHE. PAHs could undergo many natural attenuation processes including biodegradation, adsorption, volatilization, photolysis, and chemical degradation (Haritash and Kaushik, 2009). The high removal efficiency of PHE in the presence of green tide algae $U$. prolifera demonstrated a potential new natural attenuation process for typical PAHs in coastal water during the outbreak of green tide. LCSM, which was a real-time tool for direct observation of organic pollutant within plant (Wang et al., 2012), was used in this study. PHE fluorescence was clearly observed in both live and heat-killed $U$. prolifera (Fig. 2), confirming the engagement of $U$. prolifera in PHE removal. The removal efficiency of PHE in the live algae treatments under both sterilization $\left(\mathrm{T}_{1}\right)$ and without sterilization $\left(\mathrm{T}_{2}\right)$ were similar, indicating that plant accumulation but not the microbial biodegradation was the main removal process in the presence of $U$. prolifera.

The PHE contents in live $\left(\mathrm{T}_{1}\right)$ and heat-killed algae $\left(\mathrm{CK}_{2}\right)$ were detected as $0.26 \mu \mathrm{g} \mathrm{g}^{-1}$ and $0.76 \mu \mathrm{g} \mathrm{g}^{-1}$, respectively, confirming the

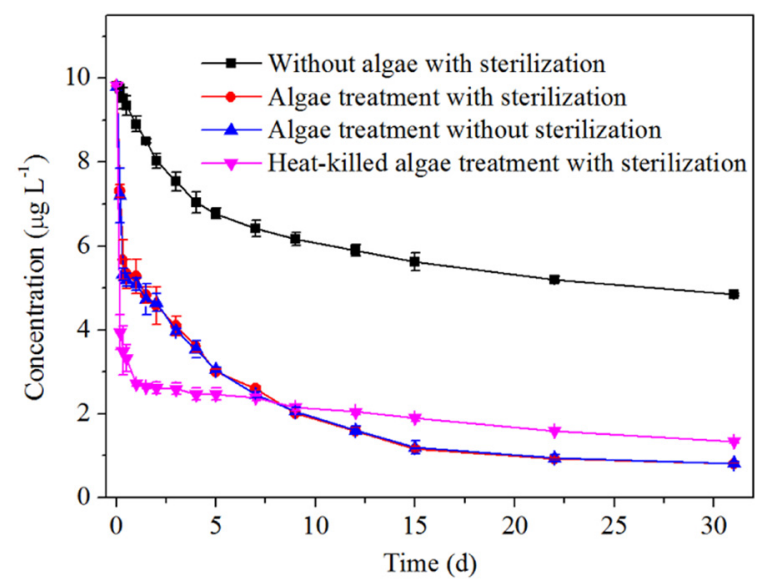

Fig. 1. Changes in phenanthrene concentrations in seawater during incubation. 

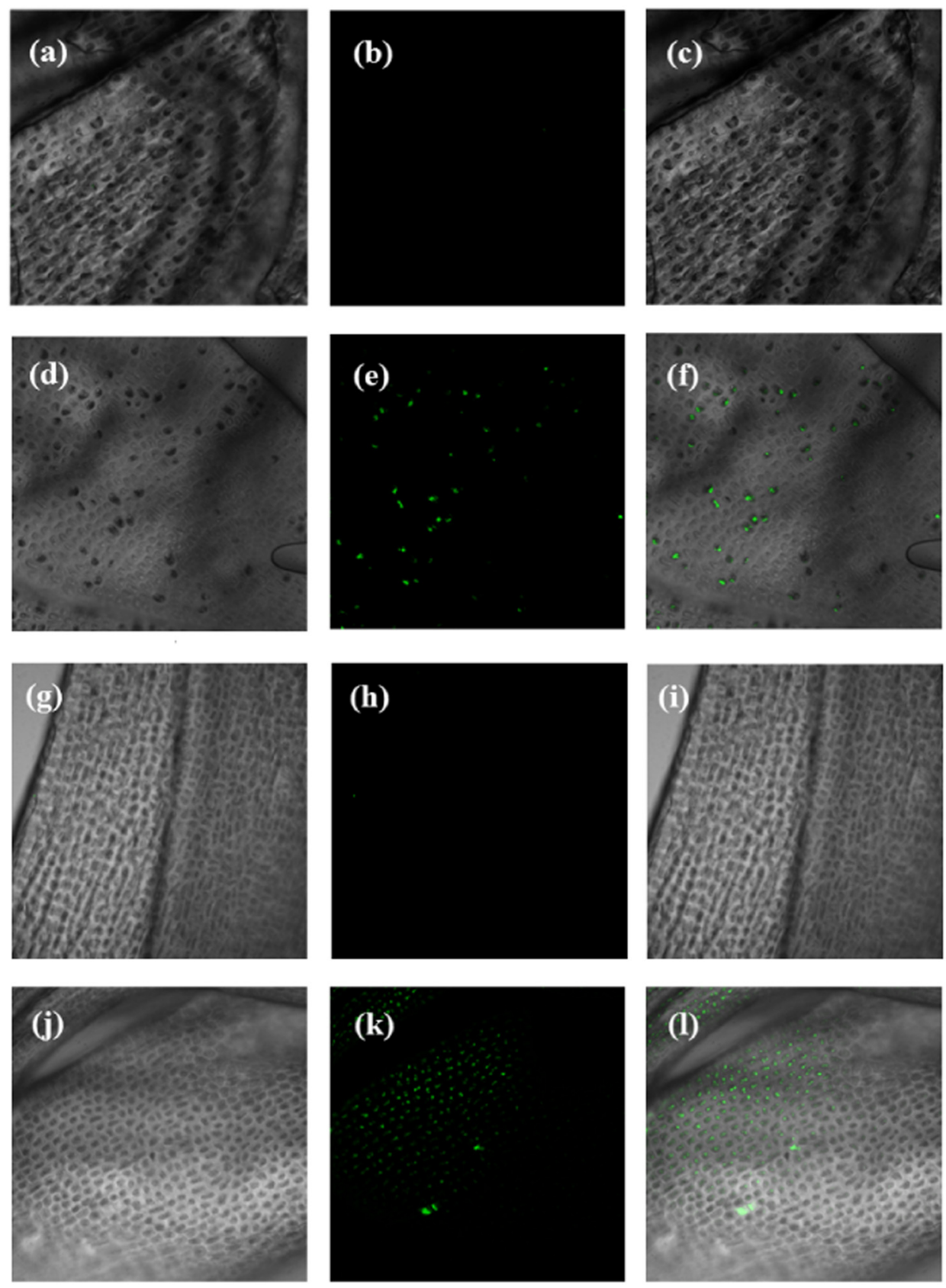

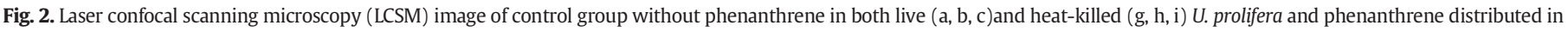
both live $(\mathrm{d}, \mathrm{e}, \mathrm{f})$ and heat-killed $(\mathrm{j}, \mathrm{k}, \mathrm{l})$ U. prolifera under brightfield image $(\mathrm{a}, \mathrm{d}, \mathrm{g}, \mathrm{j})$, green fluorescence image $(\mathrm{b}, \mathrm{e}, \mathrm{h}, \mathrm{k})$ and overlay image $(\mathrm{c}, \mathrm{f}, \mathrm{i}, \mathrm{l})\left(\times 10, \lambda_{\mathrm{ex}}=405 \mathrm{~nm}\right)$.

engagement of algae in the removal of PHE. According to the mass balance, $30.4 \%$ of the PHE was detected in the algae biomass in the heatkilled algae treatment $\left(\mathrm{CK}_{2}\right)$ while $10.4 \%$ of the PHE was detected in the live algae treatment $\left(T_{1}\right)$. Since PHE was readily degraded in algae (Chan et al., 2010), the rational explanation was that the degradation of PHE in algae was also an important approach for the removal of PHE besides the abiotic loss ( $>50 \%$ ) (mainly through photodegradation and volatilization) (Haritash and Kaushik, 2009).

Compared with the control without algae $\left(\mathrm{CK}_{1}\right)$, rapid removal of PHE occurred in the treatments with algae $\left(\mathrm{CK}_{2}\right.$ and $\left.\mathrm{T}_{1}\right)$. According to Fig. 1, the PHE concentration decreased rapidly from $10.00 \mu \mathrm{g} \mathrm{L}^{-1}$ to $2.71 \mu \mathrm{g} \mathrm{L}^{-1}$ within one day in the presence of heat-killed $U$. prolifera $\left(\mathrm{CK}_{2}\right)$. Investigations have shown that dead algae possess impressive adsorptive removal for pollutants (Javadian et al., 2013). Luo et al. (2014) reported that Benz[a]anthracene and benzo[a]pyrene were highly transformed in both live and dead microalgae (Selenastrum capricornutum), and dead cells displayed greater transformation levels than live cells. Dead Selenastrum capricornutum also showed a good performance on the removal of phenanthrene, fluoranthene, and pyrene (Chan et al., 2010). Similar rapid removal of PHE occurred first from day 0 to day 1 in the living algae treatments $\left(T_{1}\right)$, followed with another rapid removal process occurring from day 1 to day 15 , indicating that there were two-stage rapid removal processes in the living algae treatment. One reasonable explanation was that the PHE was mainly removed through a rapid adsorptive removal process and then followed a plant uptake process in the live algae treatments. The principle mechanism involved appears to be physico-chemical adsorption which is metabolism independent (Tam et al., 2002). Algae provided many potential binding sites to pollutants due to the presence of polysaccharides, proteins or lipid on their cell wall surfaces, thus the adsorptive removal process was similar for live and dead algal biomass (Avery et al., 1998). The process of heat-killing can increase the permeability of the cell wall of 

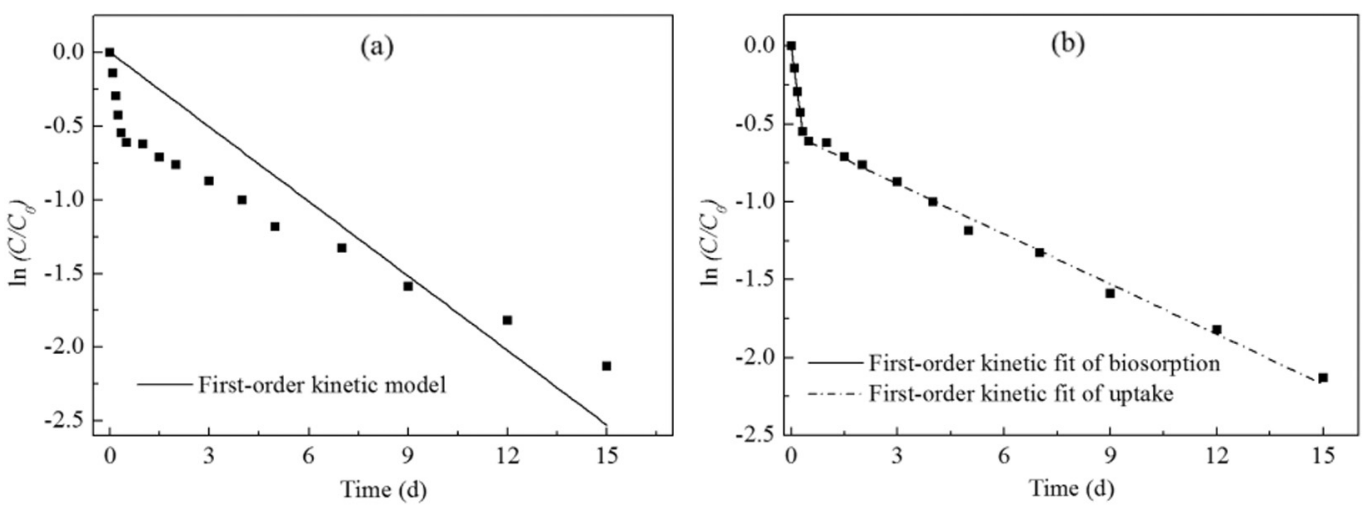

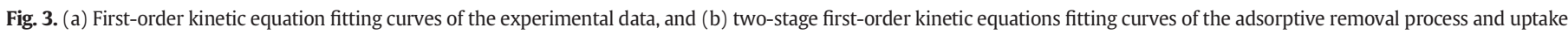
process.

algae, and thereafter additional binding sites might become more available in dead algal cell in certain cases (Avery et al., 1998), which leads to the relatively high adsorptive removal efficiency in the heat-killed algae control $\left(\mathrm{CK}_{2}\right)$.

\subsection{Removal kinetics}

To better know the removal behaviors of PHE in the presence of U. prolifera, the removal kinetics was investigated. In this study, firstorder kinetic (Eq. (1)) was used to correlate the experimental data:

$\ln C_{t}=\ln C_{0}-k t$

where $C_{0}$ and $C_{t}$ are PHE concentration at time 0 and t days, respectively; $k\left(\mathrm{~d}^{-1}\right)$ is the first-order degradation rate constant.

The removal data did not fit first-order kinetic model well $\left(\mathrm{R}^{2}<\right.$ 0.900 ) (Fig. 3a). According to the removal data of the live algae treatment $\left(T_{1}\right)$, it was supposed that the PHE was mainly removed through a rapid adsorptive removal process (process I) and then followed by a plant uptake process (process II) in the live algae treatment. Based on this hypothesis, two-stage first-order model was applied for the removal process (Fig. $3 \mathrm{~b}$ ). The constant $k$ for the rapid adsorptive removal $\left(k_{\mathrm{a}}\right)$ was $1.69 \mathrm{~d}^{-1}\left(\mathrm{R}^{2}=0.999\right)$, while that of the second-stage plant uptake process $\left(k_{u}\right)$ was $0.11 \mathrm{~d}^{-1}\left(\mathrm{R}^{2}=0.993\right)$.

\subsection{Effect of photoperiod on PHE removal}

According to Fig. 4, the light had influence on the removal of PHE. During the 31-day exposure with different photoperiod, the removal

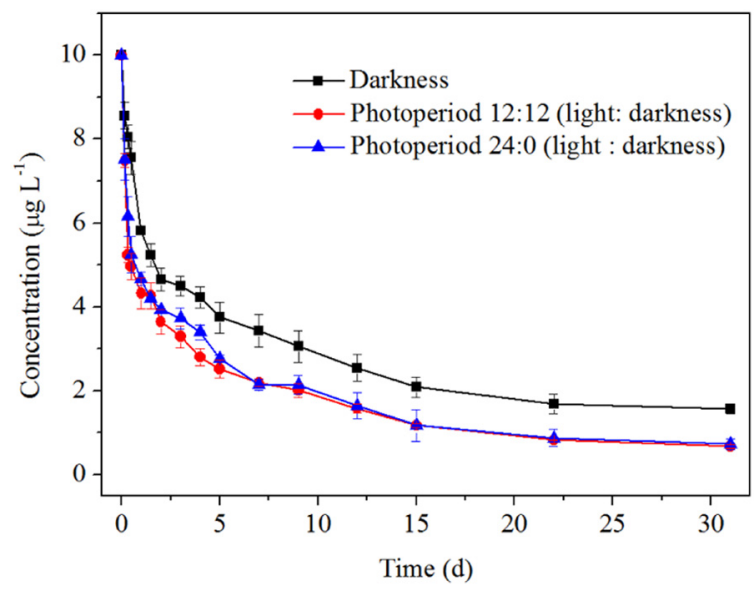

Fig. 4. Effect of photoperiod on the removal of phenanthrene by U. prolifera. efficiency in the darkness treatment, photoperiod 12:12 (light: darkness) treatment, and photoperiod 24:0 (light:darkness) treatment were $84.2 \%, 91.8 \%$, and $91.3 \%$, respectively. The complete darkness had lower removal efficiency, confirming that PHE removal efficiency was influenced by light irradiation. According to Neumann et al. (2003), the complete darkness has lower algae Se removal rate compared with treatment with a $16 \mathrm{~h}$ light period. Algae need light for photosynthesis to convert light energy into chemical energy used for further metabolic activities (Singh and Singh, 2015). The complete darkness might inhibit the metabolic activities of $U$. prolifera, which subsequently led to the decrease in the removal efficiency of PHE. The removal of PHE in the photoperiod 12:12 (light:darkness) treatment was similar to that of the photoperiod 24:0 (light:darkness) treatment, indicating that the exposure time with light has no obvious influence on PHE removal.

\subsection{Effect of salinity on PHE removal}

In the case of salinity, an increase in salinity did not have a significant effect on the removal efficiency of PHE. The removal rate was found to be similar as the salinity increased from $16 \mathrm{~g} \mathrm{~L}^{-1}$ to $32 \mathrm{~g} \mathrm{~L}^{-1}$ (Fig. 5). Being an intertidal species, $U$. prolifera has wide salinity tolerance (Mou et al., 2013). For this reason, there was no effect of salinity on the removal of PHE.

\subsection{Effect of nutrient on PHE removal}

According to the experimental results (Fig. 6), the removal of PHE from the culture system was accomplished through two periods. At the first 7 days, PHE removal rate showed a tendency to increase as the nutrient concentration increased. The removal efficiencies under nutrient concentration of $0 \mu \mathrm{M}\left(\mathrm{NO}_{3}^{-}\right) / 0 \mu \mathrm{M}\left(\mathrm{PO}_{4}^{2-}\right), 50 \mu \mathrm{M}\left(\mathrm{NO}_{3}^{-}\right) / 5$ $\mu \mathrm{M}\left(\mathrm{PO}_{4}^{2-}\right)$, and $150 \mu \mathrm{M}\left(\mathrm{NO}_{3}^{-}\right) / 15 \mu \mathrm{M}\left(\mathrm{PO}_{4}^{2-}\right)$ were $73.5,75.4$, and $80.2 \%$, respectively. The tendency of removal rate became similar during the last 24 days exposure because the added nutrient was depleted. The results of kinetic fitting showed that the $k_{\mathrm{a}}$ values were similar among these three treatments, while the $k_{u}$ values could increase from $0.56 \mathrm{~d}^{-1}$ to $0.83 \mathrm{~d}^{-1}$ with the nutrient content increasing (Fig. 6). Thus, withdrawal of nutrients by $U$. prolifera in eutrophic water appeared to greatly enhance the removal rates of PHE.

\subsection{Effect of temperature on PHE removal}

Temperature strongly influences the cellular chemical composition, uptake of nutrients, and the growth rates of algae (Singh and Singh, 2015), which might has great influence on the removal of PHE in the presence of $U$. prolifera. Fig. 7 showed that the removal efficiency of PHE by $U$. prolifera was greatly influenced by temperature. The removal constant $k_{\mathrm{a}}$ at adsorption stage increased from $1.41 \mathrm{~d}$ to $1.91 \mathrm{~d}^{-1}$, while 


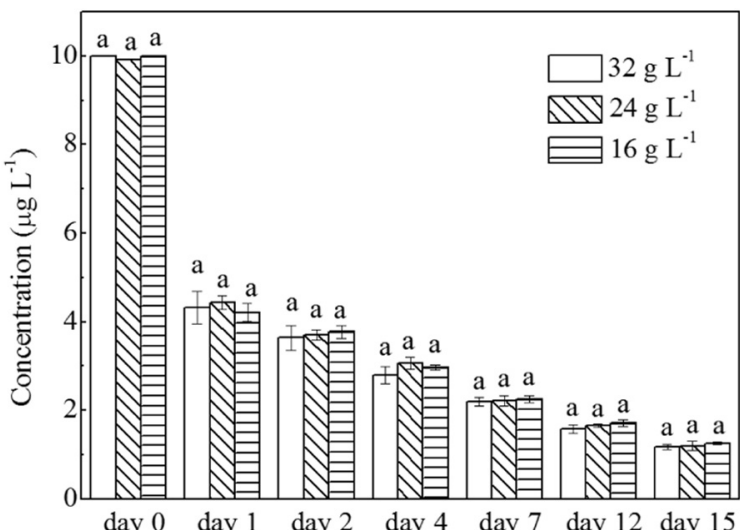

Fig. 5. Effect of salinity on the removal of phenanthrene by U. prolifera. Same letters on top of the bar indicate the means are not significantly different at $\mathrm{P} \leq 0.05$ according to oneway ANOVA test.

the uptake constant $k_{u}$ increased slightly from $0.06 \mathrm{~d}^{-1}$ to $0.11 \mathrm{~d}^{-1}$ when the temperature increased from $10{ }^{\circ} \mathrm{C}$ to $30{ }^{\circ} \mathrm{C}$. The increase in temperature led to the increase in the removal efficiency of PHE, which was similar with other report on the removal of remazol black B dye using green alga Chlorella vulgaris (Aksu and Tezer, 2005).

\subsection{Effect of initial concentration of PHE on PHE removal}

Average removal rate as a function of initial concentration was shown in Fig. 8. Increase in the initial concentration of PHE resulted in increased average removal rate, accompanying with a linear relationship between initial concentration and the average removal rate $\left(R^{2}=0.999\right)$ (Fig. 8). The maximum average removal rate could reach $5.77 \mu \mathrm{g} \mathrm{d}^{-1}$. It is generally accepted that the removal rate increases in linear proportion to the substrate concentration only at very low substrate concentrations while high initial concentration might have possible toxicity which would subsequently inhibit the removal efficiency by organisms (Lu et al., 2008). However, in our study, this linear relationship maintained even at relatively high initial concentration, indicating that the toxic effect had not occurred even at very high initial concentrations. According to previous investigation, the concentration of PAHs in water over the East China Sea ranges from 0.01 to about $2 \mu \mathrm{g} \mathrm{L}^{-1}$ (Men et al., 2009; Qiu et al., 2009; Wang et al., 2007). High PHE removal efficiency (91.3\%) was achieved when the initial PHE concentration was set at environmental relevant concentration $\left(5 \mu \mathrm{g} \mathrm{L}^{-1}\right)$, indicating that $U$. prolifera might efficiently remove PHE

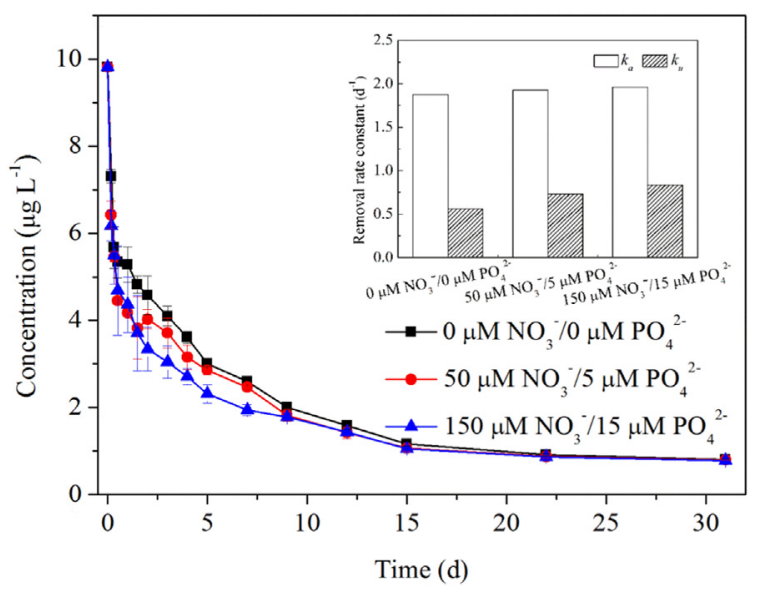

Fig. 6. Effect of nutrient on the removal of phenanthrene by $U$. prolifera. Inset: First-order rate constant for adsorptive removal $\left(k_{\mathrm{a}}\right)$, and plant uptake removal $\left(k_{u}\right)$ at different nutrient concentration.

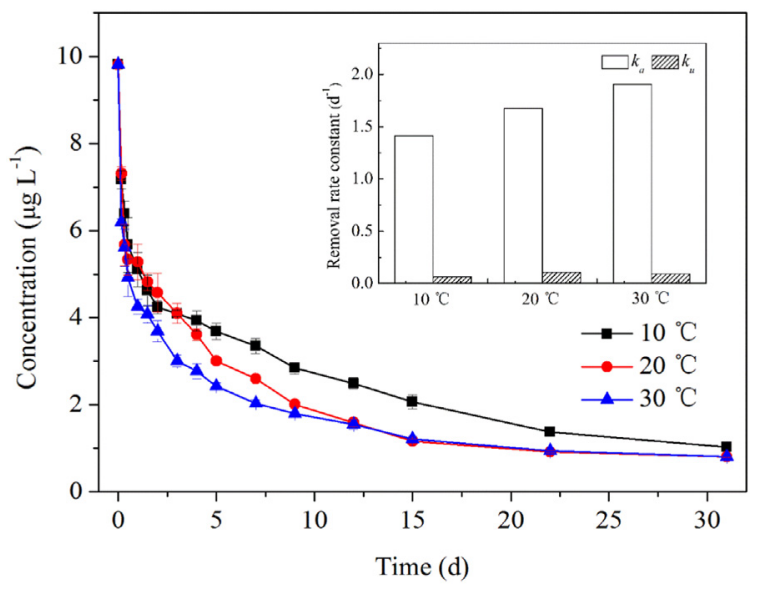

Fig. 7. Removal of phenanthrene by $U$. prolifera at different temperatures. Inset: First-order rate constant for adsorptive removal $\left(k_{\mathrm{a}}\right)$, and plant uptake removal $\left(k_{u}\right)$ at different temperatures.

from coastal water within its floating area during the outbreak of green tide.

\section{Conclusions}

Results of this study demonstrate a potential new natural attenuation process for typical PAHs in coastal water during the outbreak of green tide. The efficient removal of PHE in the presence of $U$. prolifera collected from the coastal water during the outbreak of green tide was observed. The nutrient and temperature had positive influence on the removal efficiency of PHE. The ability of $U$. prolifera on contaminant removal can be effective in coastal water under various saline conditions since the salinity had no significant effect on PHE removal efficiency. The removal efficiency by $U$. prolifera had a good linear relationship with PHE initial concentration even at $100 \mu \mathrm{g} \mathrm{L}^{-1}$ which was higher than its environmentally relevant concentrations. High removal efficiency was observed even when the initial PHE concentration was set at environmental relevant concentration, indicating that $U$. prolifera might efficiently remove PHE from coastal water within its floating area during the outbreak of green tide. These findings indicate that the outbreak of harmful green tide algae may bring positive environmental benefit in the terms of removing harmful organic pollutants from the coastal waters.

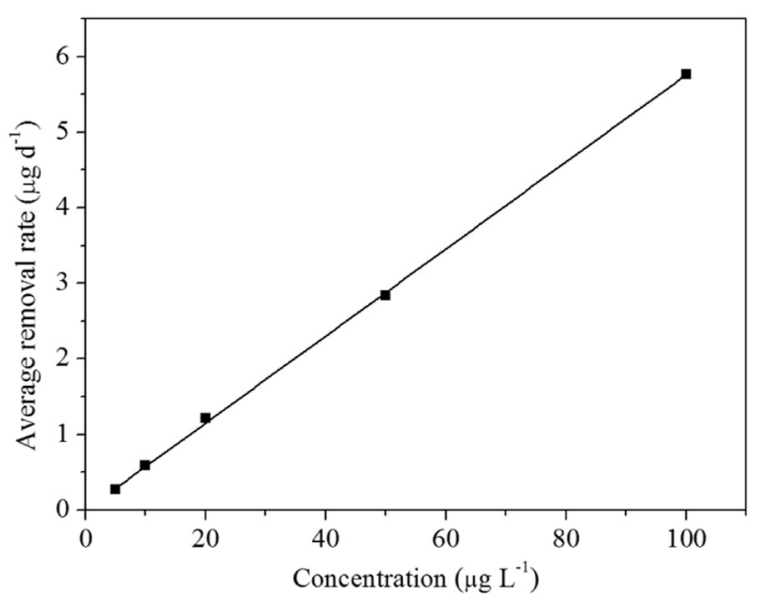

Fig. 8. Average removal rate as a function of the initial concentration of phenanthrene $\left(R^{2}\right.$ $=0.999$ ). 


\section{Acknowledgements}

This work was financially supported by One Hundred-Talent Plan of Chinese Academy of Sciences (Grant numbers of Y629041021 and Y610061033), National Natural Science Foundation of China (No. 41671319), Two-Hundred Talents Plan of Yantai (Y739011021), and Research Program of CAS Key Laboratory of Coastal Environmental Processes and Ecological Remediation (No. 1189010002). The authors would like to thank the reviewers for their valuable suggestions and comments on the manuscript.

\section{References}

Aksu, Z., Tezer, S., 2005. Biosorption of reactive dyes on the green alga Chlorella vulgaris. Process Biochem. 40, 1347-1361.

Augusto, S., Máguas, C., Matos, J., Pereira, M.J., Branquinho, C., 2010. Lichens as an integrating tool for monitoring PAH atmospheric deposition: a comparison with soil, air and pine needles. Environ. Pollut. 158, 483-489.

Avery, S.V., Codd, G.A., Gadd, G.M., 1998. Microalgal removal of organic and inorganic metal species from aqueous solution. In: Wong, Y.-S., Tam, N.F.Y. (Eds.), Wastewater Treatment with Algae. Springer, Berlin, Heidelberg, pp. 55-72.

Cabello-Pasini, A., Macías-Carranza, V., Abdala, R., Korbee, N., Figueroa, F.L., 2011. Effect of nitrate concentration and UVR on photosynthesis, respiration, nitrate reductase activity, and phenolic compounds in Ulva rigida (Chlorophyta). J. Appl. Phycol. 23, 363-369.

Chan, S.M.N., Luan, T., Ming, H.W., Tam, N.F.Y., 2010. Removal and biodegradation of polycyclic aromatic hydrocarbons by Selenastrum capricornutum. Environ. Toxicol. Chem. $25,1772-1779$.

Diaz, M., Mora, V., Pedrozo, F., Nichela, D., Baffico, G., 2015. Evaluation of native acidophilic algae species as potential indicators of polycyclic aromatic hydrocarbon (PAH) soil contamination. J. Appl. Phycol. 27, 321-325.

D'Sa, E., Overton, E.B., Lohrenz, S.E., Maiti, K., Turner, R.E., Freeman, A., 2016. Changing dynamics of dissolved organic matter fluorescence in the northern gulf of Mexico following the Deepwater Horizon oil spill. Environ. Sci. Technol. 50, 4940-4950.

Fan, X., Xu, D., Wang, Y., Zhang, X., Cao, S., Mou, S., Ye, N., 2014. The effect of nutrient concentrations, nutrient ratios and temperature on photosynthesis and nutrient uptake by Ulva prolifera: implications for the explosion in green tides. J. Appl. Phycol. 26, 537-544.

Gao, G., Zhong, Z., Zhou, X., Xu, J., 2016. Changes in morphological plasticity of Ulva prolifera under different environmental conditions: a laboratory experiment. Harmful Algae 59, 51-58.

Haritash, A.K., Kaushik, C.P., 2009. Biodegradation aspects of polycyclic aromatic hydrocarbons (PAHs): a review. J. Hazard. Mater. 169, 1-15.

Javadian, H., Ahmadi, M., Ghiasvand, M., Kahrizi, S., Katal, R., 2013. Removal of $\mathrm{Cr}(\mathrm{VI})$ by modified brown algae Sargassum bevanom from aqueous solution and industrial wastewater. J. Taiwan Inst. Chem. E. 44, 977-989.

Juhasz, A.L., Naidu, R., 2000. Bioremediation of high molecular weight polycyclic aromatic hydrocarbons: a review of the microbial degradation of benzo[a]pyrene. Int. Biodeter. Biodegr. 45, 57-88.

Kim, K.-H., Jahan, S.A., Kabir, E., Brown, R.J.C., 2013. A review of airborne polycyclic aromatic hydrocarbons (PAHs) and their human health effects. Environ. Int. 60, 71-80.

Li, H., Zhang, Y., Han, X., Shi, X., Rivkin, R.B., Legendre, L., 2016. Growth responses of Ulva prolifera to inorganic and organic nutrients: implications for macroalgal blooms in the southern Yellow Sea. China. Sci. Rep. 6.

Lu, J., Jin, Q., He, Y., Wu, J., Zhang, W., Zhao, J., 2008. Anaerobic degradation behavior of nonylphenol polyethoxylates in sludge. Chemosphere 71, 345.

Luo, M.B., Liu, F., Xu, Z.L., 2012. Growth and nutrient uptake capacity of two co-occurring species, Ulva prolifera and Ulva linza. Aquat. Bot. 100, 18-24.

Luo, L., Wang, P., Lin, L., Luan, T., Ke, L., Tam, N.F.Y., 2014. Removal and transformation of high molecular weight polycyclic aromatic hydrocarbons in water by live and dead microalgae. Process Biochem. 49, 1723-1732.

Men, B., He, M., Tan, L., Lin, C., Quan, X., 2009. Distributions of polycyclic aromatic hydrocarbons in the Daliao River Estuary of Liaodong Bay, Bohai Sea (China). Mar. Pollut. Bull. 58, 818-826.

Mou, S., Zhang, X., Dong, M., Fan, X., Xu, J., Cao, S., Xu, D., Wang, W., Ye, N., 2013. Photoprotection in the green tidal alga Ulva prolifera: role of LHCSR and PsbS proteins in response to high light stress. Plant Biol. 15, 1033-1039.
Muratova, A., Dubrovskaya, E., Golubev, S., Grinev, V., Chernyshova, M., Turkovskaya, O., 2015. The coupling of the plant and microbial catabolisms of phenanthrene in the rhizosphere of Medicago sativa. J. Plant Physiol. 188, 1-8.

Neumann, P.M., Souza, M.P.D., Pickering, I.J., Terry, N., 2003. Rapid microalgal metabolism of selenate to volatile dimethylselenide. Plant Cell Environ. 26, 897-905.

Pedetta, A., Pouyte, K., Herrera Seitz, M.K., Babay, P.A., Espinosa, M., Costagliola, M., Studdert, C.A., Peressutti, S.R., 2013. Phenanthrene degradation and strategies to improve its bioavailability to microorganisms isolated from brackish sediments. Int. Biodeter. Biodegr. 84, 161-167.

Pugazhendi, A., Qari, H., Al-Badry Basahi, J.M., Godon, J.J., Dhavamani, J., 2017. Role of a halothermophilic bacterial consortium for the biodegradation of PAHs and the treatment of petroleum wastewater at extreme conditions. Int. Biodeter. Biodegr. 121, 44-54.

Qiu, Y.-W., Zhang, G., Liu, G.-Q., Guo, L.-L., Li, X.-D., Wai, O., 2009. Polycyclic aromatic hydrocarbons (PAHs) in the water column and sediment core of Deep Bay, South China. Estuar. Coast. Shelf. S. 83, 60-66.

Shang, J., Chen, J., Shen, Z., Xiao, X., Yang, H., Wang, Y., Ruan, A., 2015. Photochemical degradation of PAHs in estuarine surface water: effects of DOM, salinity, and suspended particulate matter. Environ. Sci. Pollut. Res. 22, 12374-12383.

Shi, X., Qi, M., Tang, H., Han, X., 2015. Spatial and temporal nutrient variations in the Yellow Sea and their effects on Ulva prolifera blooms. Estuar. Coast. Shelf. S. 163 (Part A) 36-43.

Singh, S.P., Singh, P., 2015. Effect of temperature and light on the growth of algae species: a review. Renew. Sust. Energ. Rev. 50, 431-444.

Sinha, S., Chattopadhyay, P., Sen, S.K., 2012. Microbial degradation of recalcitrant PAHsMicrobial diversity involving remediation process. In: Singh, S.N. (Ed.), Microbial Degradation of Xenobiotics. Springer, Berlin, Heidelberg, pp. 395-410.

Suman, S., Sinha, A., Tarafdar, A., 2016. Polycyclic aromatic hydrocarbons (PAHs) concentration levels, pattern, source identification and soil toxicity assessment in urban traffic soil of Dhanbad, India. Sci. Total Environ. 545-546, 353-360.

Tam, N.F.Y., Chong, A.M.Y., Wong, Y.S., 2002. Removal of tributyltin (TBT) by live and dead microalgal cells. Mar. Pollut. Bull. 45, 362-371.

Wang, J., Guan, Y., Ni, H., Luo, X., Zeng, E.Y., 2007. Polycyclic aromatic hydrocarbons in riverine runoff of the Pearl river delta (China): concentrations, fluxes, and fate. Environ. Sci. Technol. 41, 5614-5619.

Wang, P., Wu, T.-H., Zhang, Y., 2012. Monitoring and visualizing of PAHs into mangrove plant by two-photon laser confocal scanning microscopy. Mar. Pollut. Bull. 64 1654-1658.

Wang, J., Liu, J., Ling, W., Huang, Q., Gao, Y., 2017. Composite of PAH-degrading endophytic bacteria reduces contamination and health risks caused by PAHs in vegetables. Sci. Total Environ. 598, 471-478.

Wu, Y., Kerr, P.G., Hu, Z., Yang, L., 2010a. Removal of cyanobacterial bloom from a biopond-wetland system and the associated response of zoobenthic diversity. Bioresour. Technol. 101, 3903-3908.

Wu, Y., Zhang, S., Zhao, H., Yang, L., 2010b. Environmentally benign periphyton bioreactors for controlling cyanobacterial growth. Bioresour. Technol. 101, 9681-9687.

Wu, Y., Liu, J., Yang, L., Chen, H., Zhang, S., Zhao, H., Zhang, N., 2011. Allelopathic control of cyanobacterial blooms by periphyton biofilms. Environ. Microbiol. 13, 604.

Xia, K., Hagood, G., Childers, C., Atkins, J., Rogers, B., Ware, L., Armbrust, K., Jewell, J., Diaz, D., Gatian, N., 2012. Polycyclic aromatic hydrocarbons (PAHs) in Mississippi seafood from areas affected by the Deepwater Horizon oil spill. Environ. Sci. Technol. 46, 5310-5318.

Xu, D., Zhang, X., Wang, Y., Fan, X., Miao, Y., Ye, N., Zhuang, Z., 2016. Responses of photosynthesis and nitrogen assimilation in the green-tide macroalga Ulva prolifera to desiccation. Mar. Biol. 163, 9.

Zhang, X., Dong, X., Mao, Y., Li, Y., Xue, S., Jian, Z., Wei, L., Liang, C., Zhuang, Z., Wang, Q. 2011. Settlement of vegetative fragments of Ulva prolifera confirmed as an important seed source for succession of a large-scale green tide bloom. Limnol. Oceanogr. 56, 233-242.

Zhang, D., Wang, J.-J., Ni, H.-G., Zeng, H., 2017. Spatial-temporal and multi-media variations of polycyclic aromatic hydrocarbons in a highly urbanized river from South China. Sci. Total Environ. 581-582, 621-628.

Zhao, X., Qiu, H., Zhao, Y., Shen, J., Chen, Z., Chen, J., 2015. Distribution of polycyclic aromatic hydrocarbons in surface water from the upper reach of the Yellow River Northwestern China. Environ. Sci. Pollut. Res. 22, 6950-6956.

Zhu, Y.D., Yang, Y.Y., Liu, M.X., Zhang, M.M., Wang, J., 2014. Concentration, distribution, source, and risk assessment of PAHs and heavy metals in surface water from the Three Gorges Reservoir, China. Hum. Ecol. Risk Assess. 21, 1-15.

Zhu, M., Liu, Z., Shao, H., Jin, Y., 2016. Effects of nitrogen and phosphate enrichment on the activity of nitrate reductase of Ulva prolifera in coastal zone. Acta Physiol. Plant. 38, 169 